\title{
Tissue Engineering of Bone: Critical Evaluation of Scaffold Selection
}

\author{
Itzhak Binderman ${ }^{1}$, Avinoam Yaffe ${ }^{2}$, Yuval Samuni³, \\ Hila Bahar ${ }^{1}$, Joseph Choukroun ${ }^{4}$ and Philippe Russe ${ }^{5}$ \\ ${ }^{1}$ Department of Oral Biology, Maurice and Gabriela Goldschleger, \\ School of Dental Medicine, Sackler Faculty of Medicine, Tel Aviv University, \\ 2Department of Prosthodontics, Haddasah School \\ of Dental Medicine, Hebrew University of Jerusalem, \\ ${ }^{3}$ Department of Oral and Maxillofacial Surgery, Barzilai Medical Center, Ashkelon, \\ ${ }^{4}$ Syfac, Nice, \\ ${ }^{5}$ Private Practice, Reims, \\ 1,2,3 Israel \\ 4,5 France
}

\section{Introduction}

The first report on tissue engineering (TE) dates back to the book of Genesis where "...the Lord God sent a deep sleep on the man, and took one of the bones from his side while he was sleeping, joining up the flesh against its place" ( Genesis ). Interestingly and perhaps inadvertently, the importance of bone as a scaffold in the process of tissue engineering was acknowledged even in the scriptures. The ultimate goal of TE is to regenerate and replace structural and functional deficits of tissue, beyond its natural healing capacity. For that purpose, external regenerative resources including scaffolds, cells and growth/trophic factors (GF) either alone or in combination are employed (Place et al., 2009; Tanner, 2010; Rokn et al., 2011). The general strategy of TE uses undifferentiated cells seeded within a scaffold which defines the geometry of the replacement tissues, and provides environmental cues to promote the development of new tissues (Zuk, 2008;,Place et al., 2009; Binderman et al., 2011.). It is now well understood that the cell-scaffold interaction is a crucial part of TE and should mimic the interaction between cell surface receptors and the extracellular matrix (ECM). The ECM, composed of various macromolecules such as proteoglycans, collagens, laminins, fibronectins and sequestered growth factors, is responsible for regulating cellular functions including survival, adhesion, proliferation, migration, differentiation, and matrix deposition (Binderman et al., 2011). Furthermore, it is now widely accepted that bone matrix and its cellular environment constitute one of the best known niche of adult stem cells both for hematopoiesis and mesenchymal tissues (Ferrer, et al., 2010). Given the complexity of living tissue, current approach for TE does not support attempts to recreate tissue ex vivo. Instead, one should develop synthetic materials that will establish key interactions with cells and unlock the body's innate powers of organization and self-repair (Place et al., 2009; 
Binderman et al., 2011). This principal of using the body as a "bioreactor" guides our development strategy for TE of bone (Stevens, et al., 2005).

Autografts and allogenic grafts are routinely used in the clinic. Nevertheless, the morbidity associated with harvesting of autografts and their limited availability, and the inferior mechanical properties of allogenic grafts have spurred the search for the optimal artificial bone substitute material. Numerous artificial bone grafts are commercially available. These include macroporous bioactive ceramic granules made from calcium sulphate, tricalcium phosphate (ß-TCP), synthetic hydroxyapatite (HA), and biphasic calcium phosphate (a mixture of TCP and HA) (Hing, 2004; Jones et al., 2010). Although widely used, calcium sulphate and to a lesser extent TCP, dissolve very rapidly, often resulting in a new defect. HA on the other hand degrades very slowly, thus impeding the apposition of new bone. In fact, osteoprogenitor cells in conjunction with scaffold and osteogenic factors were used to create bone tissue both in vitro and in vivo (Binderman,et al., 2011). These engineered bone grafts have been shown to posses the capacity for osteogenesis, but also for osteoconduction and even bioactivity. Ideally, the engineered bone should form a structural and functional connection with the host bone, also termed as physical connectivity. Unfortunately, vascularization of engineered bone tissue remains a major obstacle in achieving a clinically sized bone grafts.

While the physical and chemical requirements for scaffold composition and design for TE of bone are well defined, our ability to produce them is still limited. Scaffold should be manufactured from bioactive material that allows attachment of cells to its surface and their transformation to functional osteoblasts. Its design should contain macropores, 200-500 $\mu \mathrm{m}$ across, to allow in-growth of bone tissue and blood vessels, and apposition of mineralized bone matrix directly on the surface of the material (Hing et al.,2004; Zuk, 2008). On the other hand, biocompatible scaffold are less desirable since they allow formation of bone arbitrarily. Additionally, scaffold should be constructed from degradable material thus enabling the newly formed tissue to gradually replace it. Finally, scaffolds should maintain their mechanical stability and allow loading of the newly formed composite tissue. To the best of our knowledge, as of yet no such material has been reported to have all these characteristics.

This paper focuses on a specific rodent model which provides a remarkable tool for the study of TE of bone in a non-bone ectopic site. A comparative analysis of commercially available scaffolds is presented. To complement the analysis, clinical biopsies of grafted sinuses are also shown.

\section{Animal studies}

Dark Agouti (DA) inbred rats were used to study the bioactive properties of four bone graft materials (BGM), ranging from weak biocompatability to high bioactivity, namely (a) Cerabone, inorganic bovine bone treated, manufactured by aap Implantate AG, Dieburg, Germany, (b) Bio-Oss, mineral of bovine bone, manufactured by Geistlich Pharma AG, Wolhusen, Germany, (c) NanoBone, synthetic silicium rich hydroxyapatite, manufactured by Artoss GMBH, Rostock,Germany, and (d) ReproBone, synthetic tricalcium phosphate and hydroxyapatite (40:60, \%) mineral, manufactured by Ceramisys, Sheffield, England; all 
in particulate form. Our model is highly reproducible and has two major advantages: (a) bone is formed under the osteogenic environment of bone marrow and BGM, in a subcutaneos site; this way it excludes the direct effects of host bone tissue surroundings, and (b) new bone is formed within 3 weeks after implantation ( Yaffe et al.,2003; Bahar et al., 2003; Bahar et al., 2010; Binderman et al., 2011). In brief, the BGM is mixed with freshly harvested femural marrow $(3: 1, \mathrm{v} / \mathrm{v})$ of $6-8$ weeks old DA rats. The mixture is immediately implanted into a subcutaneous space prepared by blunt dissection in the thoracic region of other native DA rat (Figure 1). Three weeks later, animals were euthanized and the subcutaneous implant was harvested for microradiography and histology.

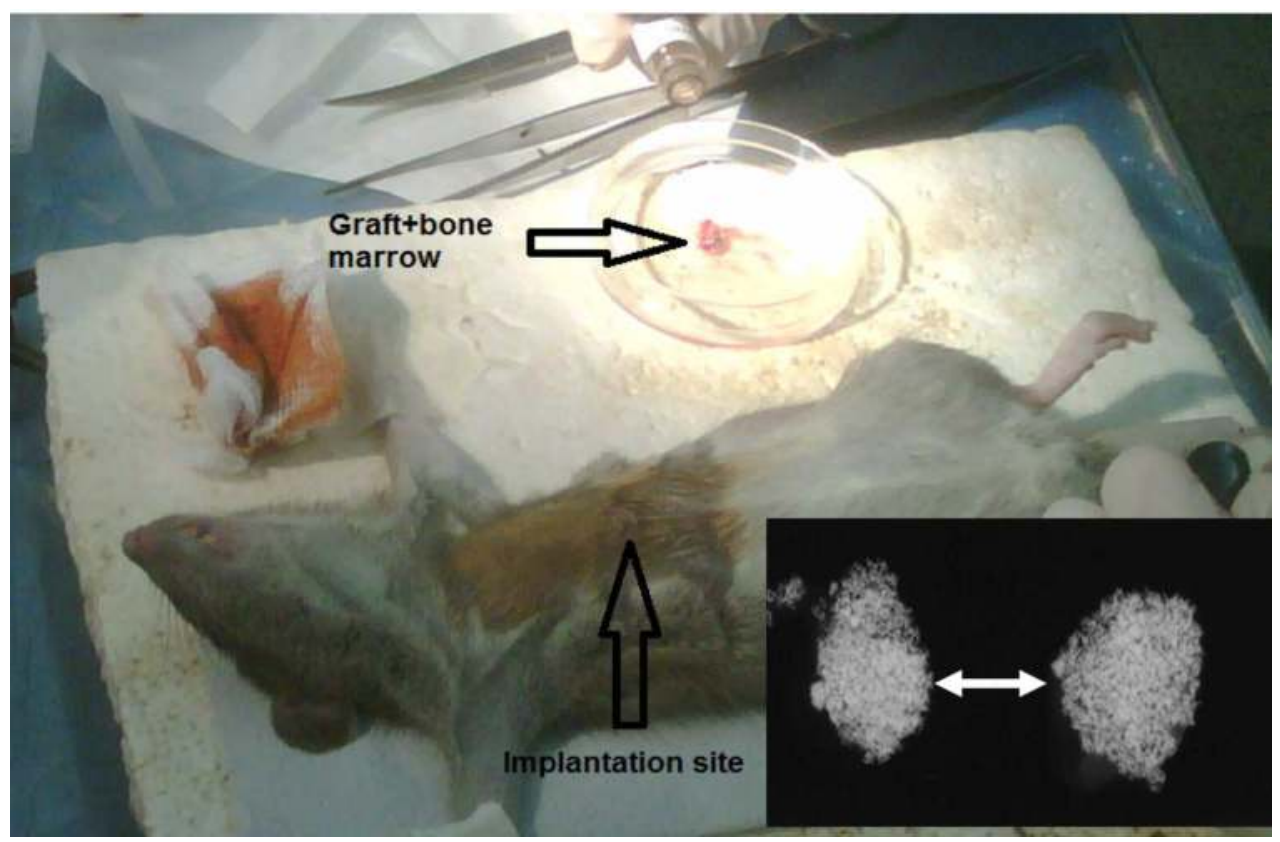

Fig. 1. Surgical implantation of BGM mixed with fresh marrow at the thoracic site of DA rats. Three weeks later the BGM implant was removed for microradiography (white arrows, x3).

Our histological evaluation included the following aspects: (i) the ability of the BGM to recruit osteogenic cells onto its surface, triggering bone deposition directly on the BGM structure, (ii) the ability of new bone to allow ingrowth of blood vessels and formation of new marrow, (iii) the recruitment of osteoclasts to resorb BGM. In this manner, a comparative analysis of commercially available BGM's was performed. Previously, we have shown histologically that fresh marrow interacting with demineralized bone matrix (DBM) of DA rats produced an ossicle consisting of a thin cortical bone surrounding numerous trabecullii which occupied new active marrow tissue (Yaffe et al.,2003; Bahar et al., 2003; Bahar et al., 2010; Binderman, 2011). Here, we compared the interaction of BGM's with fresh marrow that leads to osteogenesis in the thoracic subcutaneous site of DA rats. Moreover, we evaluated the reaction between the same BGM's in the osteogenic environment of the human maxillary sinus, on growth and deposition of bone. 
In the present study, microradiography of all implanted BGM's revealed a similar view of composite including BGM material and mineralized new bone (Fig. 1). In contrast, histological analysis demonstrated differences between the biocompatible and the bioactive BGMs as demonstrated in the following figures. Deposition of cell-rich new bone can be seen in close proximity to the particles of processed bovine bone matrix of both Cerabone (Figs. 2a and 2b) and Bio-Oss (Figs. 2c and 2d).

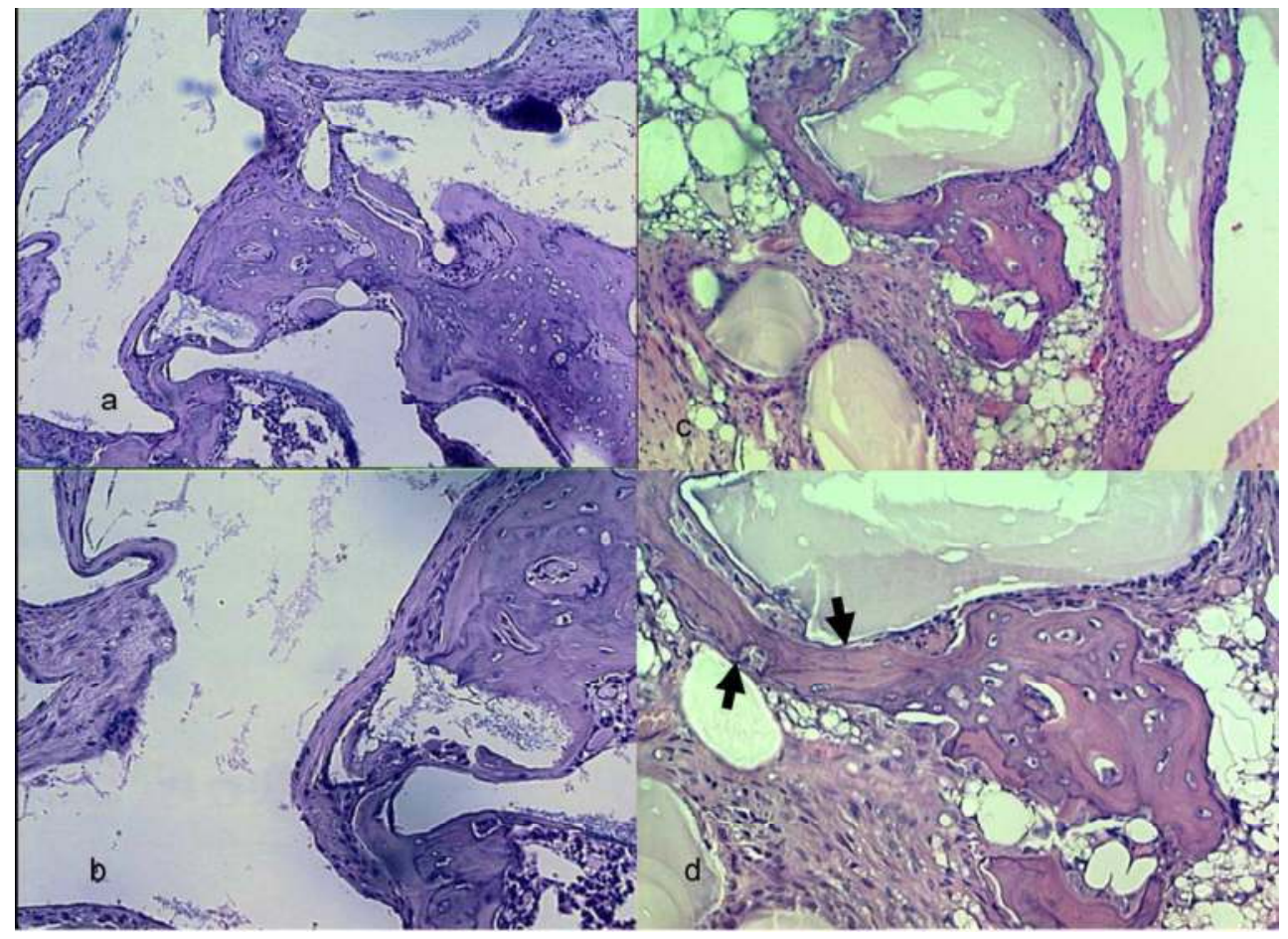

Fig. 2. Histological sections of Cerabone ( $a$ and $b$ ) and Bio-Oss (c and d), 3 weeks after implantation in DA rats. Black arrows show tight interface of Bio-Oss with bone matrix.

While most of the Cerabone surfaces were separated from the newly formed bone by layers of connective tissue including blood vessels, fibroblasts and poor matrix, some surfaces of the Bio-Oss BGM showed an intimate relationship with the new deposited bone, creating a cement line at their interface (Fig. 2d, arrow). Neither Cerabone nor Bio-Oss demonstrated active bone marrow or osteoclasts, suggesting poor resorptive properties. Although both Bio-Oss and Cerabone are composed of the mineral portion of bovine bone (no collagen was expected to be present) we found residual collagen in demineralized histological sections of Bio-Oss but not of Cerabone. The possibility exists that bone mineral may protect the organic material during the process of Bio-Oss preparation. Whether the improved biocompatability of Bio-Oss in comparison to that of Cerabone, could be attributed to the presence of bone matrix should be further investigated (Rokn et al.,2011). Nevertheless, 
these findings suggest that Bio-Oss and Cerabone are biocompatible rather than bioactive and that they have poor resorbable qualities.

NanoBone which is composed of hydroxyapatite enriched by silicium $(24 \%)$ is considered to be bioactive (Gotz et al., 2008, Jones, et al.,2010). In our DA rat system, deposition of bone was seen in intimate association and engulfing the surfaces of the Nanobone particles, indicating high bioactivity (Fig. 3).

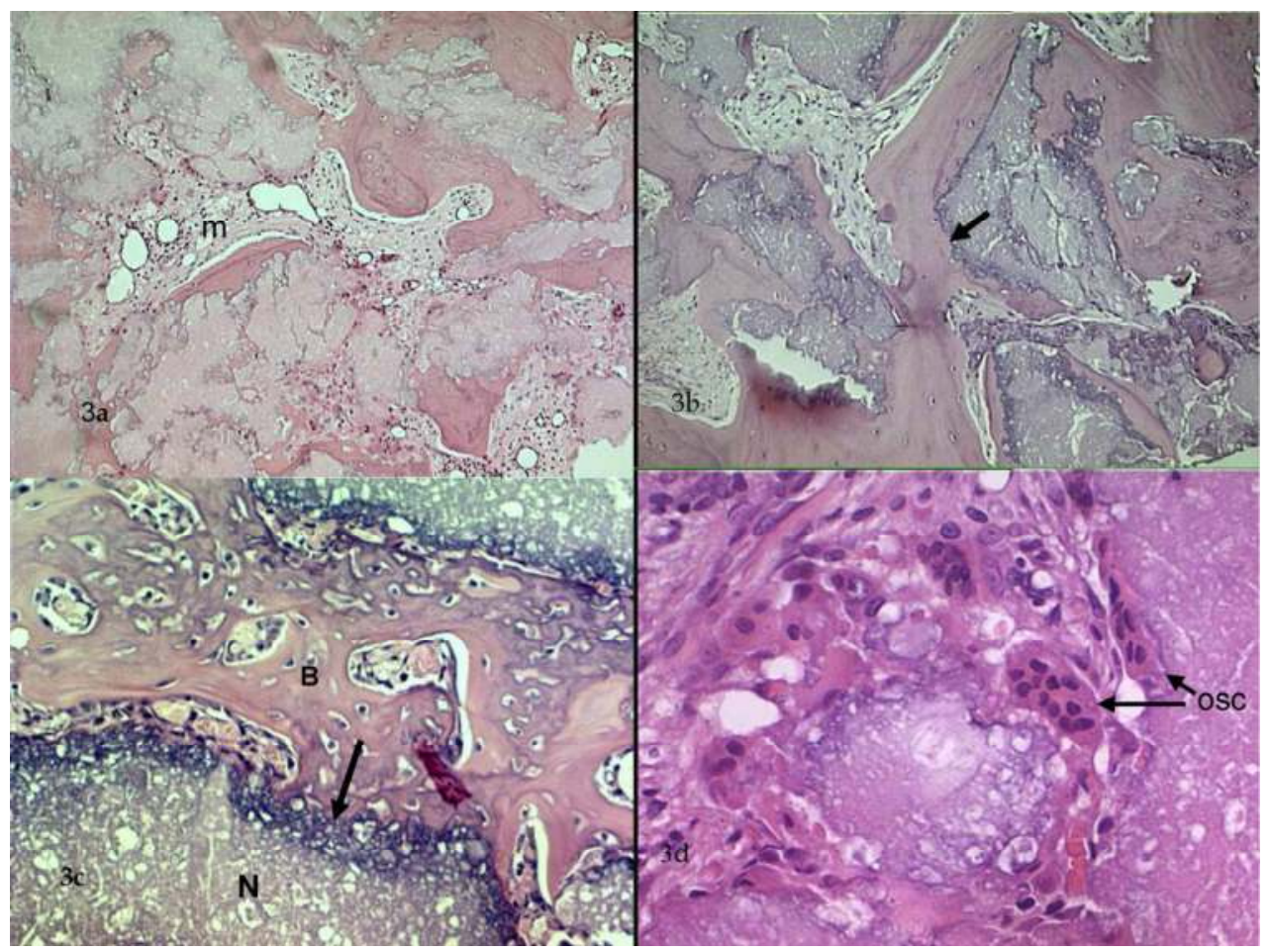

Fig. 3. Histological sections of NanoBone BGM 3 weeks after implantation. 3a shows connectivity of interfaces between bone and NanoBone; $\mathrm{m}=$ marrow spaces, including vessels and cells. $3 b$ and $3 c$ shows the bone interfaces with NanoBone by cement line (Black arrows). $\mathrm{B}=$ bone, $\mathrm{N}=\mathrm{NanoBone} \mathrm{BGM}$. 3d shows several osteoclasts (OSC), indicated by arrows on NanoBone surfaces.

Active bone marrow and many blood vessels surrounded by new bone were also seen in these histological sections. A structure of bone-BGM-bone continuity and tight connectivity of mineralized matrices that occured can provide an optimal BGM for implant anchorage and function. In the demineralized histological sections an organic residue basic material was present where the NanoBone particles reside. Because NanoBone is strictly mineral, it seems that the organic material is composed of blood proteins that are absorbed by this BGM. It was already suggested that blood proteins are absorbed mainly by silicium, thus allowing attachment of osteognic cells onto them (Jones et al.,2010). Surprisingly, in the case 
of ReproBone that is composed of $40 \%$ beta-tricalcium phosphate (B-TCP) and $60 \%$ hydroxyapatite (HA) bone was deposited directly on its surfaces, in a similar fashion observed in NanoBone bioactive BGM.

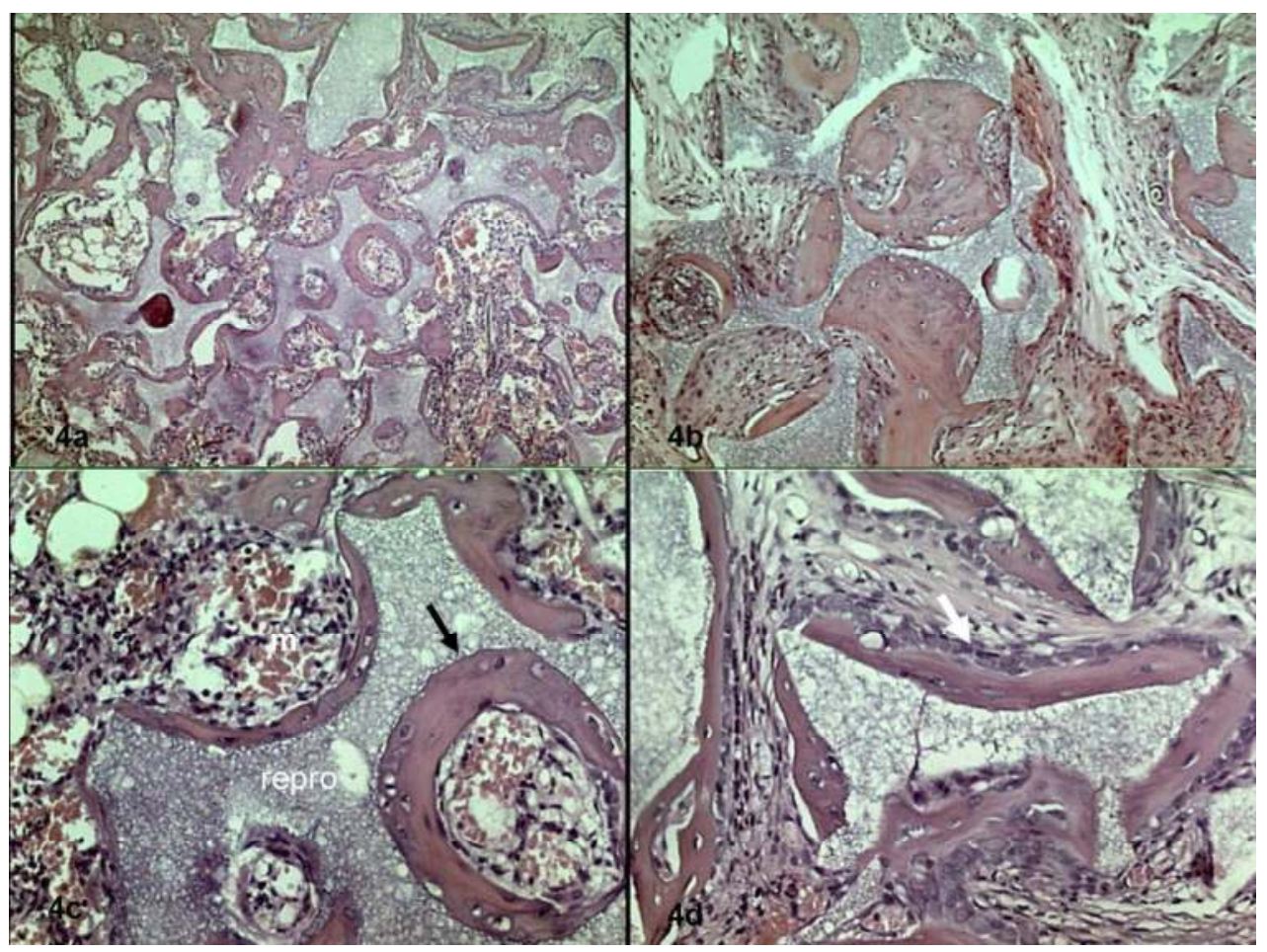

Fig. 4. Histological sections of ReproBone, 3 weeks after implantation in DA rats. $4 \mathrm{a}$ and 4b, show connectivity of bone and ReproBone througout the section. Newly formed bone is filling many of the macropores. 4c emphasizes the bone ReproBone interface (arrow), the highly active marrow and blood vessls, $\mathrm{m}=$ marrow, repro=ReproBone residual organic material. $4 \mathrm{~d}$ shows very active osteoblasts linning new bone interfacing the BGM (white arrow).

Our observation that organic basic residue is seen in demineralized histological sections of Reprobone, similar to that seen in NanoBone sections, may suggest that also here glycoproteins from the blood are strongly absorbed throughout the Reprobone material. Furthermore, Reprobone but not NanoBone allowed blood vessels ingrowth into macropores, and new bone-surrounded marrow cells to be deposited on the pores (Fig. 4, arrow). This ingrowth into macropores is reminiscent of Howship lacunae in normal bone, and was not seen in other BGM's tested in this study. The presence of osteoclasts on the surfaces of the NanoBone (Figure 3d, osc) and Reprobone indicate active remodeling and therefore high degree of bioactivity. These results support the use of Reprobone since it fulfills the criteria for an excellent BGM, namely, highly bioactive, allows blood vessels and bone ingrowth into its pores, contains active marrow and undergoes active remodeling (Figure 4). 


\section{Clinical studies}

To complement the animal data we present histological sections of BGM-grafted sinus biopsies taken from patients who underwent sinus lift procedures. All surgical procedures and biopsies were performed by Dr. Philipe Russe. In brief, under local anesthesia full thickness flap was elevated to access the anterior wall of the maxillary sinus. Using piezosugery (piezosurge III by Mectron) a bony lid was detached and the Schneiderian membrane was elevated. BGM was then placed into the sinus and rehydrated with the plated-rich-fibrin (PRF) exsudate and metronidazole (Fig. 5a). The bony window was placed back, covered with PRF membranes and the flap was sutured (Fig. 5c). 4-6 months later, bone core biopsies were taken at the implant site using a trephine (Dentsply Frios 51-4091) with external and internal diameters of 3.1 and $2 \mathrm{~mm}$, respectively (Figure 5d). Biopsies were then pushed out gently of the trephine, and taken for histology.

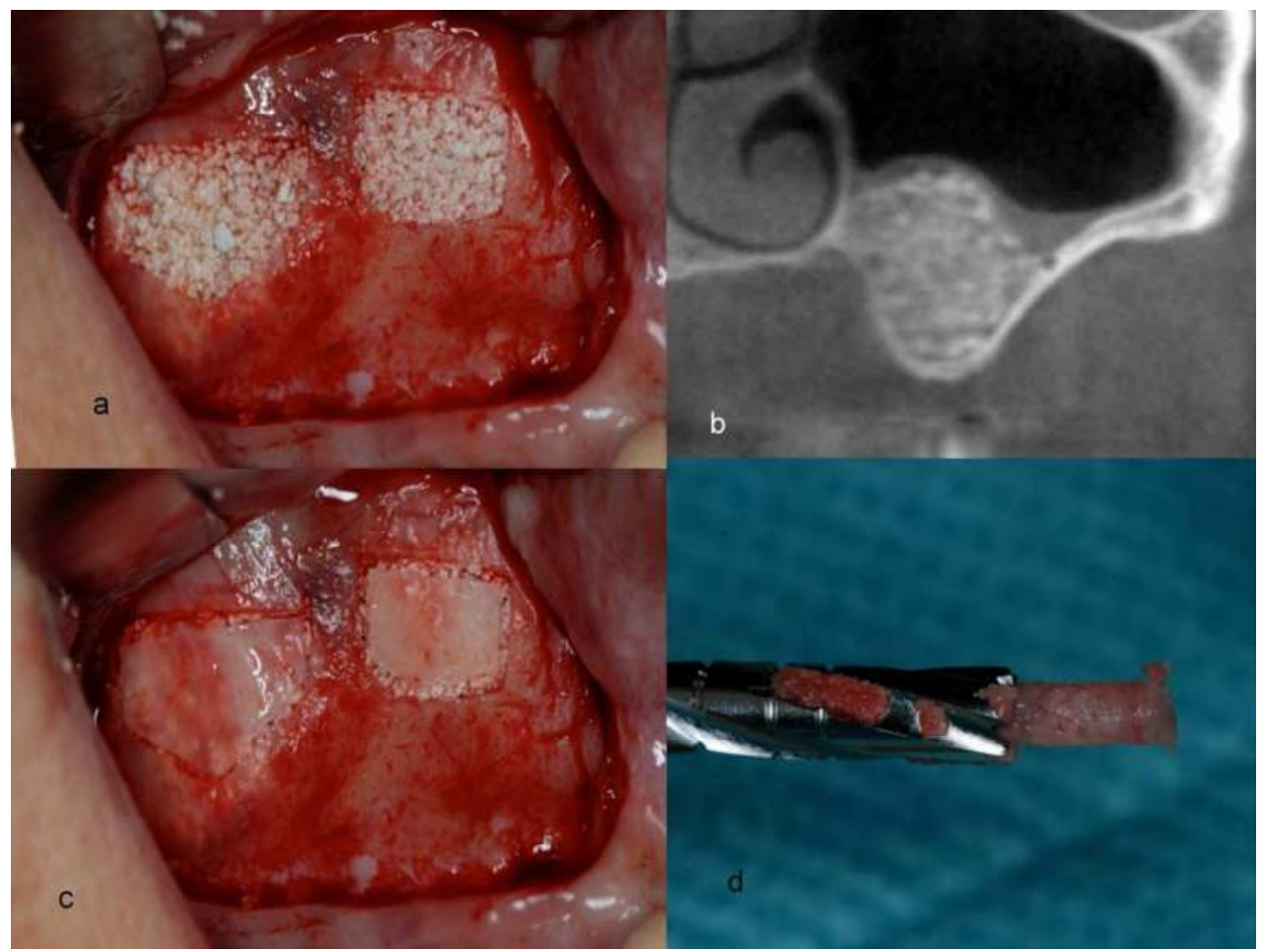

Fig. 5. (a) BGM it seen in sinus immediately after filling (b) Conen beam of sinus filled with BGM. (c) Opening of Sinus is covered by bone and PRF, before suturing back the mucosa. (d) The bone core biopsy before implant insertion (4-6 month after grafting sinus with BGM).

The osteogenic potential of the Schneiderian membrane has been previously described (Srouji, et al., 2010; Srouji, et al., 2009; Kim, et al., 2009). Histological sections from sinus grafted with Cerabone (Fig. 6c and $6 \mathrm{~d}$ ) reveal that this although considered biocompatible, the Cerabone is separated from the newly formed bone by a layers of soft connective tissue. 


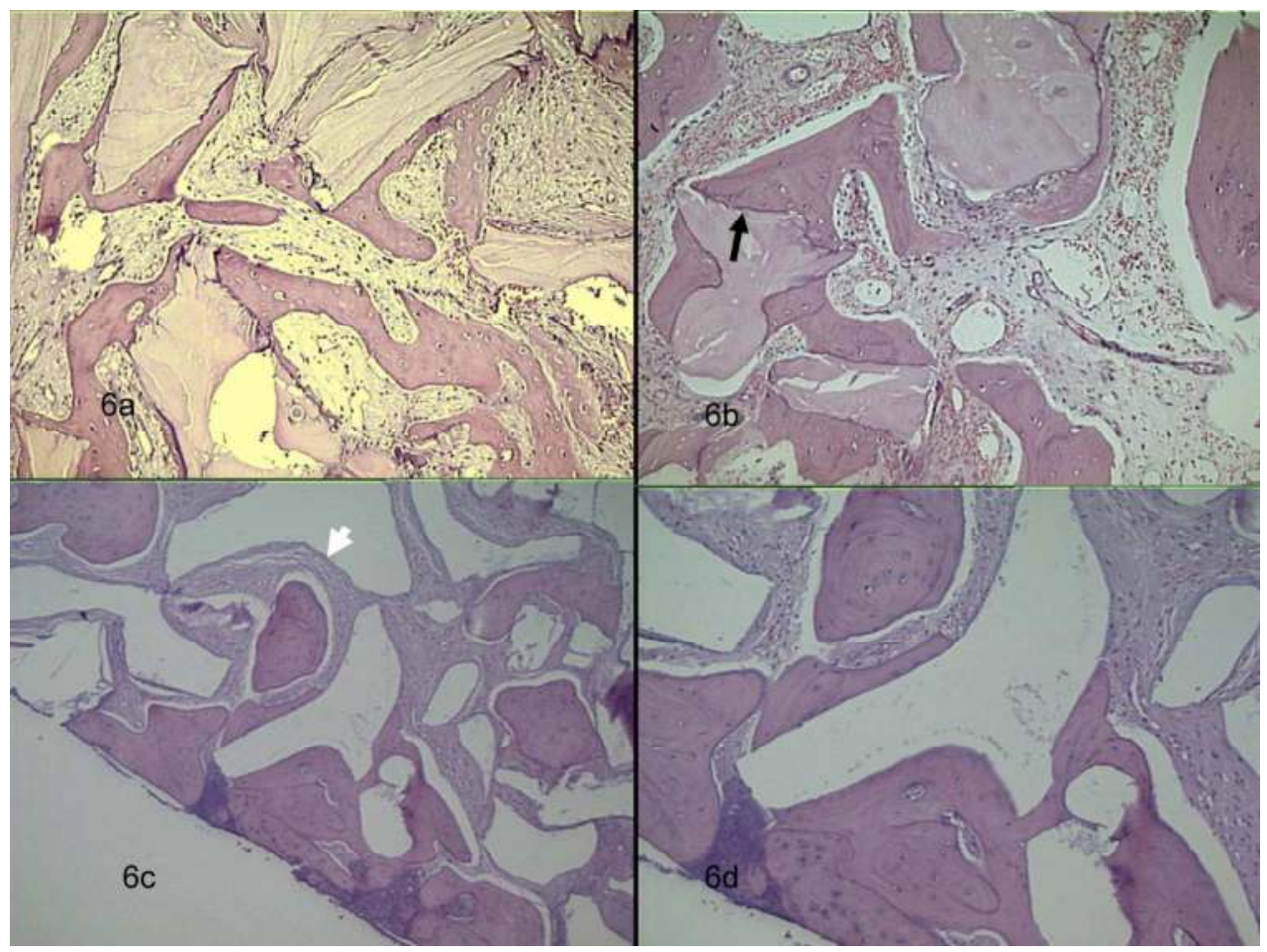

Fig. 6. Histological sections of biopsies of Bio-Oss ( $a$ and $b$ ) and Cerabone (c and d). Here we can clearly see that the interface between Bio-Oss and new bone is tight in many surfaces (black arrow in 6b), while Cerabone is separated from bone by soft connective tissue (white arrow in 6c).

Thus, the biopsy from the grafted Cerabone showed islands of grafted BGM and islands of mineralized bone, surrounded by soft connective tissue. In contrast, histological sections from biopsies of sinus grafted with Bio-Oss demonstrated new osteocyte-rich bone surrounding the Bio-Oss particles. The particles were separated from bone by few layers of connective tissue, cells and matrix and many of the Bio-Oss surfaces interphased with bone, creating a cement line of physical bond between bone and Bio-Oss (Fig. 6d, arrow). Bone could not be seen in any of the pores of this BGM. In the marrow spaces fat cells and sparse fibrous tissue, and no osteoclasts could be seen on the surfaces of Bio-Oss. Still, since it is made of cortical bone, clinicians feel that its bio-mechanical qualities are such that implants are well anchored and stabilized in the bone and Bio-Oss composite. These findings suggest that Bio-Oss is highly biocompatible and to some extent bioactive, in agreement with our animal observations. Biopsies taken from sinuses grafted with NanoBone or ReproBone presented an integrated mosaic of these BGM's and bone. A physical connectivity of BGM and bone was seen throughout the sections of both NanoBone and ReproBone. The marrow spaces were usually rich in blood cells and blood vessels, and both osteoclastic activity and matrix-producing active osteoblasts were present (Fig. 7). 


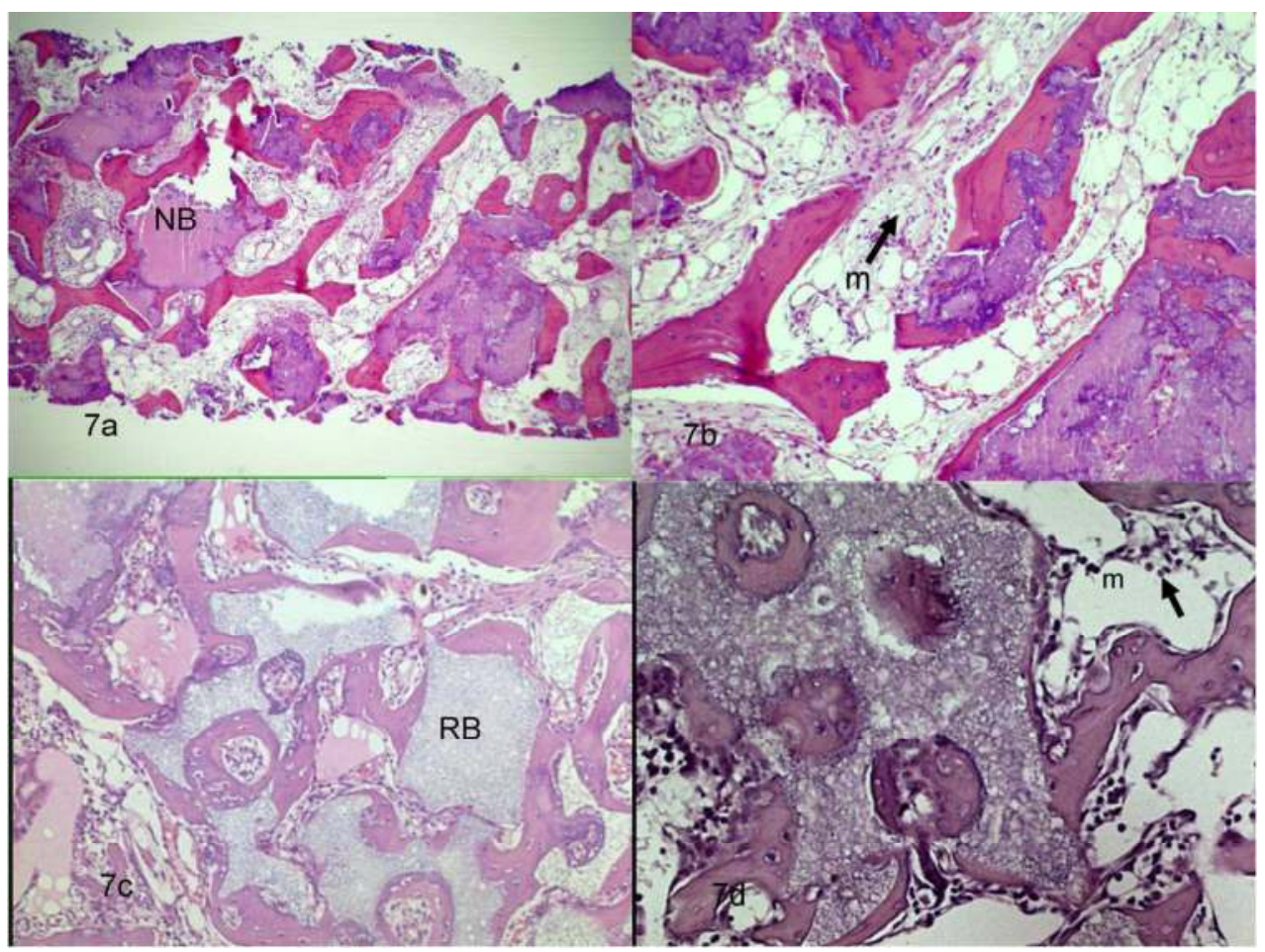

Fig. 7. Histological sections of biopsies 4-6 month after grafting in sinuses of humans. 7a and $7 \mathrm{~b}$ the BGM is NanoBone (NB). 7c and 7d sections from ReproBone (RP).

In both NB and RP sections connectivity of bone and BGM could be seen. Bone marrow $(\mathrm{m})$ was viable and blood cells were dispersed. Macropores were filled with new bone ,blood vessel and marrow. Interestingly, bone ingrowth into large pores was seen mostly in Reprobone sections but not in those of NanoBone. These results are in accord with the animal data and demonstrate the uniqueness of Reprobone in attracting ingrowth of blood vessels and bone into many of macropores. Viable marrow was seen in both NanoBone and ReproBone biopsies, indicating active bone surfaces (Ferrer, et al., 2010). This group (Ferrer,et al.,2010) proposed that hematopoietic and mesenchymal cells in marrow are much dependent on active osteoblasts. It seems that both ReproBone and NanoBone support bone formation that active in producing viable marrow and is can also undergo remodeling by osteoclasts. The data presented demonstrate the resemblance of Cerabone, Bio-Oss, NanoBone and ReproBone characteristics in the DA rat model and in human grafted sinuses.

\section{Conclusions}

In this chapter we presented a remarkable animal model for tissue engineering of bone in a non-osseous site. This model allows for bone generation in a very efficient and reproducible manner. Furthermore, it provides an in vivo measuring tool for assessing the biocompatibility and bioactivity of BGM's. Hydroxyapatite bone mineral (HA) and its 
calcium phosphate derivatives that lack the organic components of bone are considered biocompatible BGM's. They are routinely employed in bone grafting procedures to restore or fill bone defects. However, if structured to absorb serum components that can attract and bind active cells from their near environment, then these BGM's will be converted into bioactive BGM's. Consequently, the attached cells are expected to express their osteogenic phenotype and deposit bone directly on BGM's surfaces, and induce new, viable and active hematopoietic marrow in the new TE bone. Our animal studies and also clinical biopsies demonstrate that ReproBone is a highly bioactive BGM.

Of interest is our observation that Reprobone when processed as a wet moldable product to be delivered through syringe (Reprobone Novo), inhibited osteogenesis in our DA rat model (Fig. 8c and Fig. 8d). Interestingly, another product named Bonit Matrix (DOT Gmbh, Rostock, Germany) that was shown to be bioactive in our model, but when processed for delivery by syringe (Ossa Nova), demonstrated only granulation tissue surrounding the particles but no bone formation (Fig. 8a and 8b). Furthermore, multi-nucleated giant cells were also seen (Fig. 8d). We assume that these (and other) products that are intended for syringe delivery have a smaller particle size of less than $50 \mu \mathrm{m}$. Condensation of small particles may change their ability to interact with cells properly.

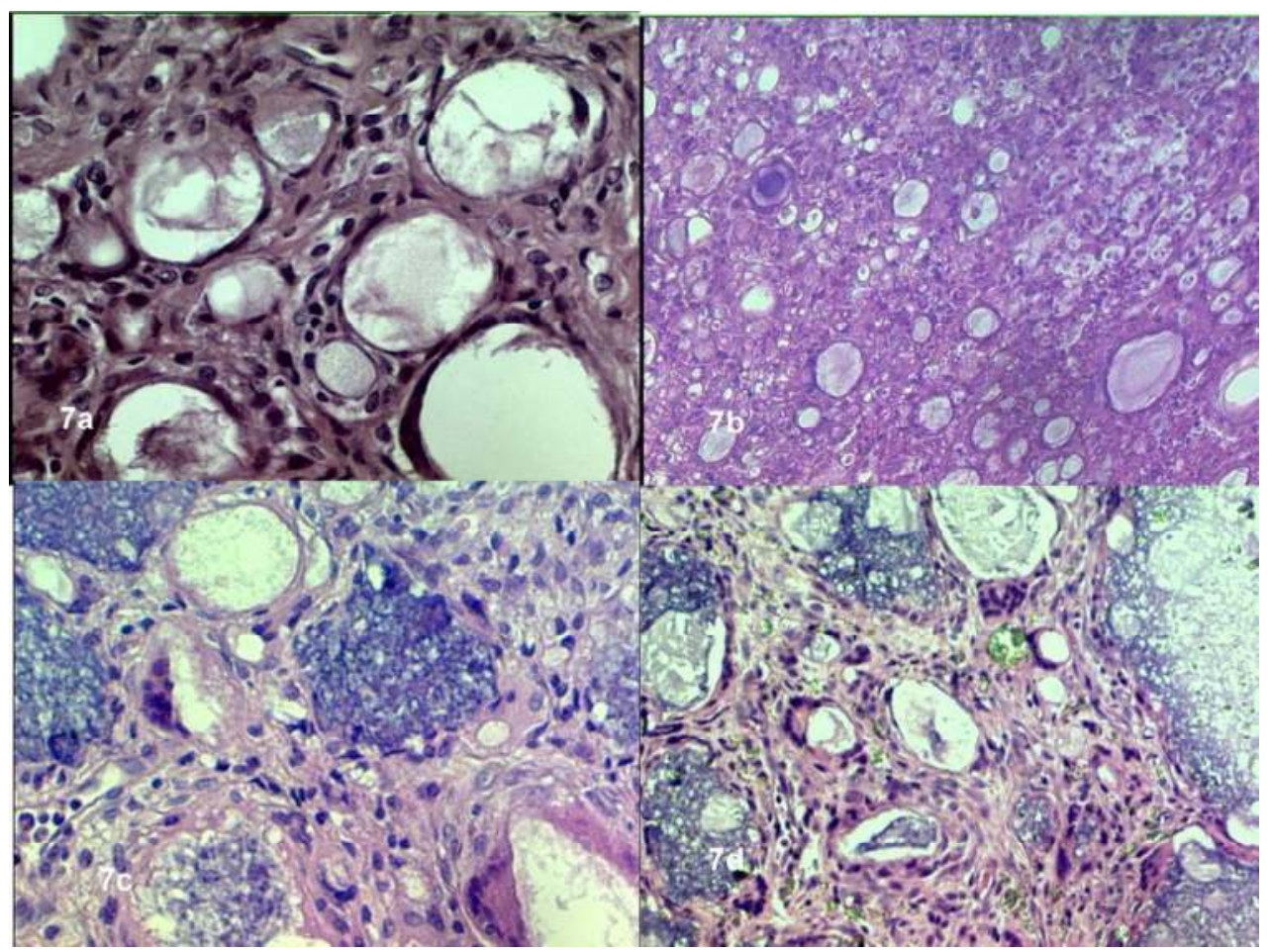

Fig. 8. Histological sections of BGM's delivered by syringe including Ossa Nova (8a and 8b) and Repro-Novo (8c and 8d). Both were mixed with bone marrow and implanted in DA rats. See in both BGM's no bone was visible. 
The process of bone engineering depends on the normal cascade of wound healing which begins with the inflammatory response. At the same time, the process requires an immediate interplay between the progenitor cells and the BGM surface. This reaction is followed by the recruitment, proliferation and differentiation of osteoprogenitor cells, synthesis of ECM proteins, and angiogenesis.

We have recently demonstrated that as soon as 3-4 days after implantation of DBM and fresh marrow in DA rats, a significant upregulation of osteoblast and of angiogenic genetic profile was measured (Bahar, et al., 2007). These findings support our view that very early after grafting, accurate and tuned interactions between the unique surface of BGM and the extracellular and cellular environment are crucial in leading the pathway for de-novo engineering of bone.

It is well accepted that continuity and connectivity of bone trabeculli is essential to the transmission of functional forces in our body. For example, in osteoporotic patients spontaneous fractures occur when trabecullii in long bones are resorbed and connectivity is disrupted. Consequently, forces are transmitted through alternative and vulnerable pathways that are unable to absorb them. We therefore propose that a clinician should use BGM's that produce physical connectivity with bone. If the mechanical properties, like strength and stiffness of the BGM are similar to that of bone, such connectivity of bone-BGM will provide an excellent biomaterial for implant function. Whether NanoBone or ReproBone physical properties are in the range of compact bone is plausible.

\section{References}

Bahar, H.; Yaffe, A.; Binderman, I.(2003). The influence of nacre surface and its modification on bone apposition: a bone development model in rats. Journal of Periodontology, 74, 366-371.

Bahar H, Benayahu D, Yaffe A, Binderman I.(2007) Molecular signaling in bone regeneration. Crit Rev Eukaryot Gene Expr., 17,(2), 87-101. Review.

Bahar, H.; Yaffe, A.; Boskey, A.; Binderman I.(2010). Influence of bone derived matrices on generation of bone in an ectopic rat model. Journal of Orthopedic Research, 28,(5), : 664-700.

Binderman, I.; Yaffe, A.; Zohar, R.; Benayahu, D.; Bahar, H. (2011). Tissue engineering of bone: an ectopic rat model. Frontiers in Biosciences (Scholar Edu), 3, 61-68.

Ferrer,S.M.; Michurina,T.V.; Ferraro,F.; Mazloom, A.R.; MacArthur, B.D.; Lira,S.A.; Scadden, D.T.; Maayan, A.; Enikolopov, G.N.; Frennete, P.S. (2010). Mesenchymal and Haematopoietic stem cells form a unique bone marrow niche. Nature, 466, 829-834.

Genesis. "And the LORD God caused a deep sleep to fall upon the man, and he slept; and He took one of his ribs, and closed up the place with flesh instead thereof. 22, And the rib, which the LORD God had taken from the man, made He a woman, and brought her unto the man". Bible, Genesis, chapter 2, sentence 21.

Gotz, W.; Gerber, T.; Lossdorfer, S.; Henkel, K.O.; Heinemann, F. (2008) Immunohistochemical characterization of nanocrystalline hydroxyapatite silica gel (Nanobone) osteogenesis: a study on biopsies from human jaws. Clin Oral Implants Res 19, 1016-1026. 
Hing, K. A.; Best, S. M.; Tanner, K. E.; Bonfield,W.; Revell, P. A. (2004). Mediation of bone ingrowth in porous hydroxyapatite bone graft substitue. J. Biomed. Mater. Res. A, , $68,187-200$.

Jones, J.R.; Lin,S.; Yue, S.; Lee,P.D.; Hanna, J.V.; Smith,M.E.; Newport, R.J. (2010). Bioactive glass scaffolds for bone regeneration and their hierarchical characterisation. Journal of Engineering in Medicine, 224, 1373-1387.

Kim, S.W.; Lee, I.K.; Yun, K.I.; Kim, C.H.; Park, J.U. (2009). Adult stem cells derived from maxillary sinus membrane and their osteogenic differentiation. Int. J Oral Maxillofac Implants, 24(6):991-998.

Place, E.S.; Evans, N.D.; Stevens, M.M. (2009) Complexity in biomaterials for tissue engineering. Nature Materials, 8, 457-470.

Rokn, A.R.; Khodadoostan, M.A.; Reza, A.A.; Ghahroudi, R.; Motahhary, P.; Fard, M.J.K.; De Bruyn, H.; Afzalifar, R.; Soolar, E.; Soolari A. (2011). Bone Formation with Two Types of Grafting Materials: A Histologic and Histomorphometric The Open Dentistry Journal, 5, 96-104.

Srouji, S.; Ben David D.; Lotan, R.; Riminucci, M.; Livne, E.; Bianco,P. (2010). The innate osteogenic potential of the maxillary sinus (Schneiderian) membrane: an ectopic tissue transplant model simulating sinus lifting. Int. J Oral Maxillofac Surgery, 39(8): 793-801.

Srouji, S.; Kizhner, Y.; Ben David D.; Riminucci, M.;Bianco,P.; Livne, E. (2009). The Schneiderian membrane contains osteoprogenitor cells: in vivo and in vitro study. Calcif Tissue Int., 84(2):138-145.

Stevens, M. M.; Marini, R.P.; Schaefer, D.; Aronson, J.; Langer, B.; Shastri, V.P. (2005) In vivo engineering of organs: the bone bioreactor. Proc. Natl Acad. Sci. USA 102, 1145011455.

Tanner, K. (2010). Bioactive composites for bone tissue engineering. Journal of Engineering in Medicine, 224, 1359-1372.

Yaffe, A.; Kollerman. R; Bahar, H.; Binderman, I.(2003) The influence of alendronate on bone formation and resorption in a rat ectopic bone development model. J J of Periodontol $74,44-50$.

Zuk, P.A. (2008). Tissue Engineering Craniofacial Defects With Adult Stem Cells? Are We Ready Yet? Pediatric Research, vol 63,(No5), 478-486. 


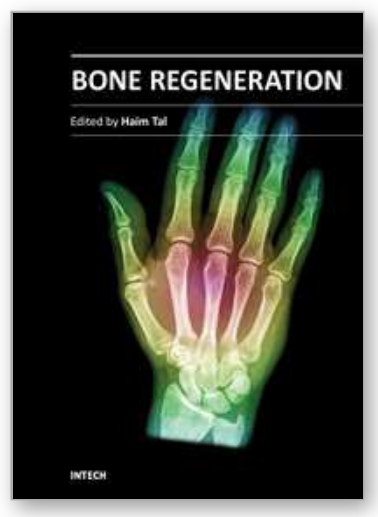

\author{
Bone Regeneration \\ Edited by Prof. Haim Tal
}

ISBN 978-953-51-0487-2

Hard cover, 340 pages

Publisher InTech

Published online 04, April, 2012

Published in print edition April, 2012

Bone is a specialized connective tissue, most prominently characterized by its mineralized organic matrix that imparts the physical properties that allow bone tissue to resist load, to support functional organs, and to protect highly sensitive body parts. Bone loss and bone damage may occur as a result of genetic conditions, infectious diseases, tumours, and trauma. Bone healing and repair, involves integrative activity of native tissues and living cells, and lends itself to the incorporation of naturally derived or biocompatible synthetic scaffolds, aimed at replacing missing or damaged osseous tissues. There are several modalities of bone regeneration including tissue engineering, guided bone regeneration, distraction ontogenesis, and bone grafting. This book concentrates on such procedures that may well be counted among the recent outstanding breakthroughs in bone regenerative therapy.

\title{
How to reference
}

In order to correctly reference this scholarly work, feel free to copy and paste the following:

Itzhak Binderman, Avinoam Yaffe, Yuval Samuni, Hila Bahar, Joseph Choukroun and Philippe Russe (2012). Tissue Engineering of Bone: Critical Evaluation of Scaffold Selection, Bone Regeneration, Prof. Haim Tal (Ed.), ISBN: 978-953-51-0487-2, InTech, Available from: http://www.intechopen.com/books/boneregeneration/tissue-engineering-of-bone-critical-evaluation-of-scaffold-selection

\section{INTECH}

open science | open minds

\author{
InTech Europe \\ University Campus STeP Ri \\ Slavka Krautzeka 83/A \\ 51000 Rijeka, Croatia \\ Phone: +385 (51) 770447 \\ Fax: +385 (51) 686166 \\ www.intechopen.com
}

\author{
InTech China \\ Unit 405, Office Block, Hotel Equatorial Shanghai \\ No.65, Yan An Road (West), Shanghai, 200040, China \\ 中国上海市延安西路 65 号上海国际贵都大饭店办公楼 405 单元 \\ Phone: +86-21-62489820 \\ Fax: +86-21-62489821
}


(C) 2012 The Author(s). Licensee IntechOpen. This is an open access article distributed under the terms of the Creative Commons Attribution 3.0 License, which permits unrestricted use, distribution, and reproduction in any medium, provided the original work is properly cited. 